\title{
Anthranilamide-masked o-Iodoarylboronic Acids as Coupling Modules for Iterative Synthesis of ortho-Linked Oligoarenes
}

\author{
Masashi Koyanagi, Nils Eichenauer, Hideki Ihara, Takeshi Yamamoto, and Michinori Suginome* \\ Department of Synthetic Chemistry and Biological Chemistry, Graduate School of Engineering, \\ Kyoto University, Katsura, Kyoto 615-8510
}

(Received February 19, 2013; CL-130136; E-mail: suginome@sbchem.kyoto-u.ac.jp)

\begin{abstract}
Anthranilamide (AAM)-masked $o$-iodoarylboronic acids were prepared from AAM-masked arylboronic acids via Rucatalyzed $o-\mathrm{C}-\mathrm{H}$ silylation, followed by iododesilylation with ICl. The Suzuki-Miyaura coupling of AAM-masked $o$-haloarylboronic acids with arylboronic acids proceeded under ligandfree conditions. Oligo(o-phenylene)s and oligo(naphthalene-2,3diyl)s were synthesized via iterative Suzuki-Miyaura coupling sequences.
\end{abstract}

Interest in the synthesis and structure of ortho-linked oligoarenes and hetarenes has been increasing. ${ }^{1-4}$ They cannot adopt planar structure, but they form helical structures due to the steric repulsion of the substituents on the aromatic rings. In addition to their static helical structures, the dynamic change in the helical structures has attracted increasing attention from the viewpoint of application to functional materials. ${ }^{5}$ For instance, we have recently established solvent-dependent, reversible switch of helical conformation of poly(quinoxaline-2,3-diyl)s with high molecular weight. ${ }^{6}$ This system was successfully applied to a new chiral catalyst system in which either enantiomer can be produced with high enantioselectivity from a single chiral catalyst. ${ }^{7}$ Although attractive, ortho-linked oligoarenes and hetarenes have not been explored in detail yet, mainly because of paucity of robust synthetic approaches. Therefore, it is highly desirable to establish general, efficient synthetic methods that would also allow the synthesis of functionalized oligoarenes in a sequence-selective manner.

We have been interested in the development of crosscoupling-based organic synthesis, including iterative synthesis of oligoarene derivatives on the basis of boron-masking strategy using 1,8-diaminonaphthalene (DAN) as a highly effective masking group. ${ }^{8}$ We subsequently established a removable ortho-directing group (o-DG), which is attached to the boron atom of the boronyl group and allows Ru-catalyzed $o$-silylation. ${ }^{9}$ Although pyrazolylaniline (PZA) was reported also as the firstgeneration $o$-DG, we subsequently showed that anthranilamide (AAM) exhibited higher ability of $o$-direction as well as higher stability, which allowed us to utilize AAM as a protective group in the Suzuki-Miyaura coupling. ${ }^{10}$ We envisioned that AAMprotected $o$-haloarylboronic acids 3 may serve as highly convenient building modules in the synthesis of helical oligo(o-arene)s via iterative Suzuki-Miyaura cross-coupling (Figure 1). The modules 3 may be obtained directly by halodesilylation of AAM-protected $o$-silylarylboronic acids 2, which in turn are conveniently prepared by $o$-silylation of AAMprotected arylboronic acids $\mathbf{1}$. It should be noted that a report on direct ortho-iodination of unprotected arylboronic acids has appeared recently. ${ }^{11,12}$ The direct iodination, however, still requires the use of silver salt to promote the reaction and

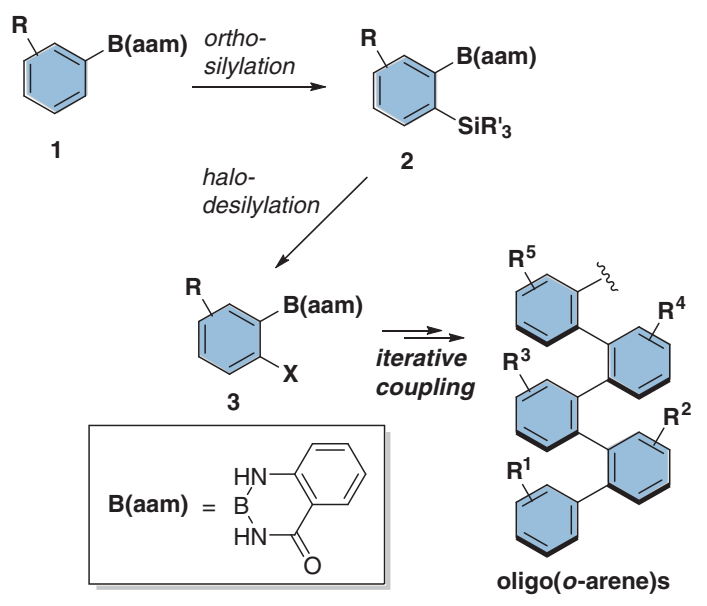

Figure 1. Synthetic strategies of oligo(o-arene)s.

encounters difficulty in iodination of electron-poor and electronneutral arenes. In this paper, we demonstrate the convenient synthesis of AAM-protected $o$-iodoarylboronic acids and their use in the iterative Suzuki-Miyaura coupling for the synthesis of oligo(o-phenylene)s and oligo(naphthalene-2,3-diyl)s.

AAM-protected $o$-silylarylboronic acids 2 were prepared according to the reported procedure for Ru-catalyzed $o$-silylation of arylboronic acids. ${ }^{10}$ In addition to the $o$-silylboronic acids $\mathbf{2 a}$, $\mathbf{2 b}, \mathbf{2 d}, \mathbf{2 g}$, and $\mathbf{2 k}$ reported in the previous paper, we also synthesized new derivatives in good yields from the corresponding AAM-protected arylboronic acids (Table 1). Iododesilylation was accomplished efficiently by use of $\mathrm{ICl}$ at a low temperature. ${ }^{12}$ Attempted use of $\mathrm{I}_{2}$ or $\mathrm{Br}_{2}$ failed to give the corresponding $o$-halogenated products in reasonable yields. In the iododesilylation, the use of the electron-deficient AAM group, rather than the electron-rich PZA group, was essential to avoid undesirable iodination on the masking group. The present synthesis of $o$-iodoarylboronic acids through iododesilylation was found to be complementary to Hall's silver-mediated direct iodination, which requires electron-donating substituents such as alkoxy and amino groups on the aromatic rings. Our method could successfully be applied to alkyl- (Entries 2 and 8), aryl(Entry 10), chloro- (Entries 5 and 11), and even fluorosubstituted arylboronic acids (Entry 6), in addition to alkoxysubstituted arylboronic acids (Entries 3 and 9). ${ }^{13}$ Note that attempted iododesilylation of the phenyldimethylsilyl group on the electron-deficient aromatic ring failed (Entry 4), leading to iodination at the phenyl group of the $\mathrm{PhMe}_{2} \mathrm{Si}$ group. This problem was overcome by use of $\mathrm{Et}_{3} \mathrm{Si}$ derivative (Entries 5, 6, 7, and 11). It should also be noted that AAM-masked 5,8dimethyl-2-naphthylboronic acid, which was used for the 
Table 1. Iododesilylation of AAM-protected $o$-silylarylboronic acids produced by Ru-catalyzed $o$-directed silylation of AAMprotected arylboronic acids ${ }^{\mathrm{a}}$

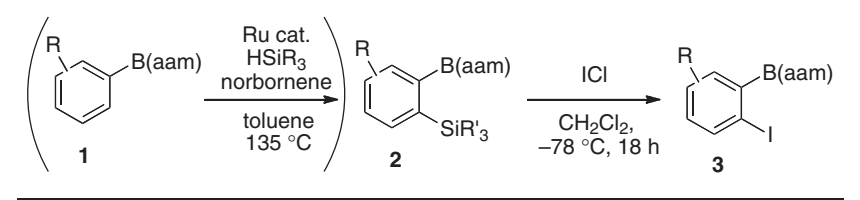

(2)

${ }^{\mathrm{a}} 2(0.1 \mathrm{mmol}), \mathrm{ICl}(0.2 \mathrm{mmol}), \mathrm{CH}_{2} \mathrm{Cl}_{2}(0.5 \mathrm{~mL}),-78^{\circ} \mathrm{C}, 18 \mathrm{~h}$. b -78 to $-9{ }^{\circ} \mathrm{C}$. ${ }^{\mathrm{c}}-78^{\circ} \mathrm{C}$ to room temperature. ${ }^{\mathrm{d}}$ Isolated yield of 2 in Ru-catalyzed ortho-silylation of the corresponding $\mathrm{ArB}(\mathrm{aam}) .{ }^{\mathrm{e}}$ Reported in ref $10 .{ }^{\mathrm{f}}$ Isolated yield.

synthesis of 21 (Entry 13) was conveniently prepared from 1,4dimethylnaphthalene via Ir-catalyzed aromatic $\mathrm{C}-\mathrm{H}$ borylation. This example demonstrates that the synthetic utility of the ortho$\mathrm{C}-\mathrm{H}$ silylation is significantly enhanced by combining it with the $\mathrm{C}-\mathrm{H}$ borylation chemistry.

We then examined cross-coupling of AAM-protected $o$ halophenylboronic acids with arylboronic acids. An initial trial
Table 2. Optimization of cross-coupling of $o$-halophenylboronic acid $\mathbf{3} \mathbf{a}^{\prime}$ with $p$-tolylboronic acid

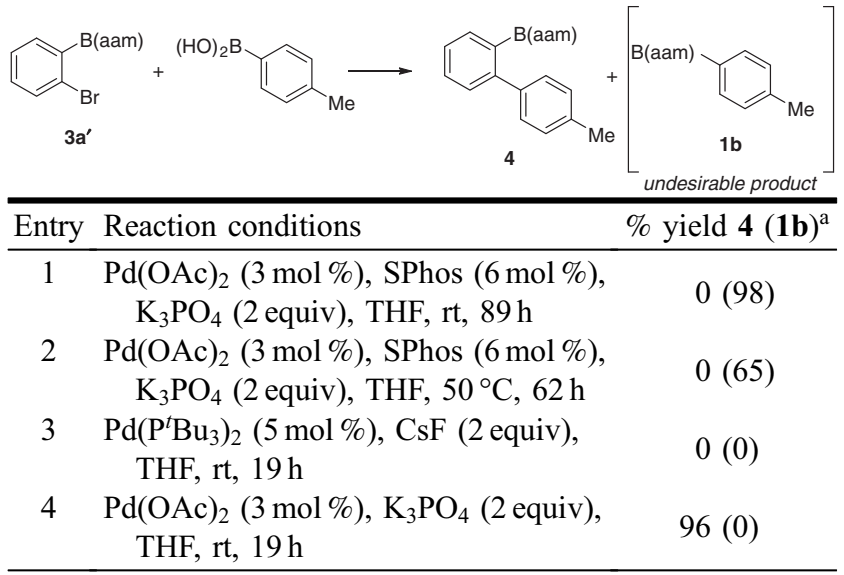

${ }^{\mathrm{a}}$ Isolated yield of $\mathbf{4}$. NMR yield of $\mathbf{1 b}$ is in the parenthesis.

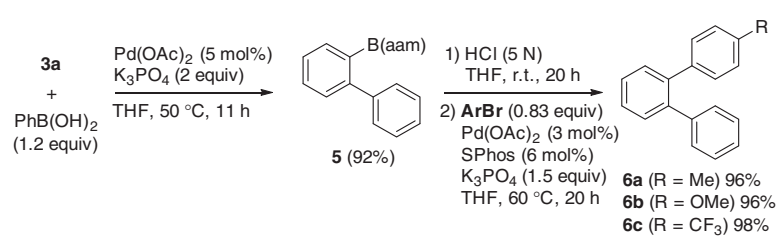

Scheme 1. Synthesis of ter(o-phenylene)s via iterative Suzuki-Miyaura coupling.

under the reaction conditions utilized for the coupling of AAMprotected $p$ - and $m$-bromophenylboronic acids completely failed, giving no desired coupling products. In fact, the attempted coupling of AAM-protected $o$-bromophenylboronic acid $\mathbf{3} \mathbf{a}^{\prime}$ in the presence of $\operatorname{SPhos}^{14}(\mathrm{P} / \mathrm{Pd}=2)$ as a ligand at room temperature resulted in transfer of the AAM group from $\mathbf{3} \mathbf{a}^{\prime}$ to $p$ tolylboronic acid, giving AAM-protected $p$-tolylboronic acid $\mathbf{1 b}$ with no formation of the coupling product (Entry 1, Table 2). Applying a higher reaction temperature did not improve the reaction outcome at all (Entry 2). Use of the $t$ - $\mathrm{Bu}_{3} \mathrm{P} / \mathrm{CsF}$ system $^{15}$ gave no desirable product, although no AAM-transfer product was formed either (Entry 3). We finally found that a ligand-free palladium catalyst worked efficiently in the crosscoupling of $\mathbf{3} \mathbf{a}^{\prime}$, giving the AAM-protected biarylboronic acid $\mathbf{4}$ in high isolated yield (Entry 4). The reaction conditions were successfully applied to the cross-coupling of $o$-iodo derivative 3a, giving the corresponding biaryl product $\mathbf{5}$ in high yield (Scheme 1). ${ }^{16}$ The thus-obtained AAM-protected biarylboronic acid 5 was cross-coupled with various aryl bromides after deprotection of the AAM group by acidic hydrolysis, giving teraryls $\mathbf{6 a - 6 c}$ in high yields.

Having established the basis for the preparation and reactivities of AAM-masked $o$-iodoarylboronic acids, we pursued the iterative synthesis of oligo(naphthalene-2,3-diyl)s using our AAM system. Cross-coupling conditions for the synthesis of oligonaphthalene were further optimized on the basis of the optimization of the biaryl synthesis shown in Table 2. We again observed better outcome with the ligand-free palladium catalyst in the coupling of AAM-masked 3-iodo-2-naphthylboronic acid 3k with 6-ethoxy-2-naphthylboronic acid (7) (Scheme 2). After 

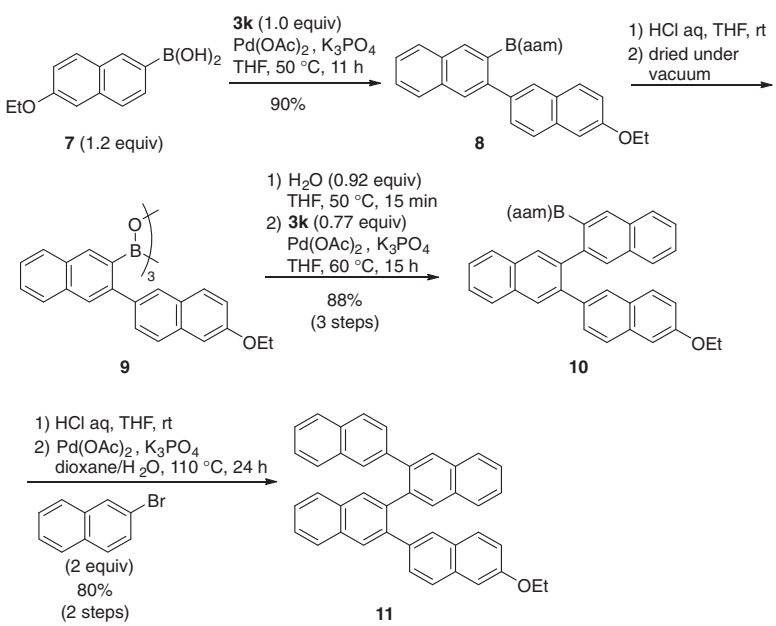

Scheme 2. Synthesis of quater(naphthalene-2,3-diyl) via iterative Suzuki-Miyaura coupling.

the coupling, the AAM group remaining untouched was removed by acidic treatment. However, use of the unmasked binaphthylboronic acid in cross-coupling with 3k resulted in illreproducible results. It turned out that the presence of even a small amount of water led to AAM transfer from 3k to the binaphthylboronic acid, whereas complete dehydration then led to the formation of boroxine 9, which was totally unreactive toward cross-coupling. Indeed, the degree of dehydration after the unmasking step significantly affected the result of the subsequent cross-coupling step. We could finally adapt the procedure in which boroxine $\mathbf{9}$, obtained by complete dehydration, was hydrolyzed to binaphthylboronic acid by adding a stoichiometric amount of water prior to the coupling step. According to this procedure, AAM-masked ternaphthylboronic acid $\mathbf{1 0}$ was isolated in high yield. The iterative coupling sequence was terminated by coupling with 2-naphthyl bromide, giving quaternaphthalene $\mathbf{1 1}$ bearing a terminal ethoxy group.

In summary, we have established a new synthetic route to $o$-iodoarylboronic acid derivatives via Ru-catalyzed $o$-directed silylation of AAM-masked arylboronic acids followed by iododesilylation with ICl. The present synthesis of $o$-iodoarylboronic acids is complementary to the ortho-directed, Agmediated iodination of arylboronic acids, ${ }^{11}$ and it shows wider applicability to electronically unactivated arylboronic acids. Application to iterative synthesis of oligo(o-phenylene)s and oligo(naphthalene-2,3-diyl)s has also been demonstrated. Synthesis of more densely functionalized oligo(o-phenylene)s and oligo(naphthalene-2,3-diyl)s, including those adapting nonracemic helical structures, are now being undertaken in this laboratory. ${ }^{17}$

This work was supported by JST, CREST. N.E. acknowledges the fellowship support from JSPS.

\section{References and Notes}

1 Oligo(o-phenylene)s: a) H. J. S. Winkler, G. Wittig, J. Org. Chem. 1963, 28, 1733. b) E. Ibuki, S. Ozasa, K. Murai, Bull. Chem. Soc. Jpn. 1975, 48, 1868. c) A. J. Blake, P. A. Cooke, K. J. Doyle, S. Gair, N. S. Simpkins, Tetrahedron Lett. 1998, 39, 9093. d) S. Ishikawa, K. Manabe, Chem. Lett. 2006, 35, 164. e) C. S.
Hartley, J. He, J. Org. Chem. 2010, 75, 8627. f) J. He, J. L. Crase, S. H. Wadumethrige, K. Thakur, L. Dai, S. Zou, R. Rathore, C. S. Hartley, J. Am. Chem. Soc. 2010, 132, 13848. g) E. Ohta, H. Sato, S. Ando, A. Kosaka, T. Fukushima, D. Hashizume, M. Yamasaki, K. Hasegawa, A. Muraoka, H. Ushiyama, K. Yamashita, T. Aida, Nat. Chem. 2011, 3, 68. h) S. M. Mathew, C. S. Hartley, Macromolecules 2011, 44, 8425. i) C. S. Hartley, J. Org. Chem. 2011, 76, 9188. j) J. He, S. M. Mathew, S. D. Cornett, S. C. Grundy, C. S. Hartley, Org. Biomol. Chem. 2012, 10, 3398. k) S. Ando, E. Ohta, A. Kosaka, D. Hashizume, H. Koshino, T. Fukushima, T. Aida, J. Am. Chem. Soc. 2012, 134, 11084.

2 Oligo(naphthalene-2,3-diyl)s: T. Motomura, H. Nakamura, M. Suginome, M. Murakami, Y. Ito, Bull. Chem. Soc. Jpn. 2005, 78, 142 .

3 Oligo(quinoline-2,3-diyl)s: M. Suginome, H. Noguchi, M. Murakami, Chem. Lett. 2007, 36, 1036.

4 Oligo- and poly(quinoxaline-2,3-diyl)s: a) Y. Ito, E. Ihara, M. Murakami, M. Shiro, J. Am. Chem. Soc. 1990, 112, 6446. b) Y. Ito, E. Ihara, M. Murakami, Angew. Chem., Int. Ed. Engl. 1992, 31, 1509. c) Y. Ito, T. Ohara, R. Shima, M. Suginome, J. Am. Chem. Soc. 1996, 118, 9188. d) Y. Ito, T. Miyake, S. Hatano, R. Shima, T. Ohara, M. Suginome, J. Am. Chem. Soc. 1998, 120, 11880 .

5 a) H. Yuki, Y. Okamoto, I. Okamoto, J. Am. Chem. Soc. 1980, 102, 6356. b) E. Yashima, Y. Maeda, Y. Okamoto, Polym. J. 1999, 31, 1033. c) M. Reggelin, S. Doerr, M. Klussmann, M. Schultz, M. Holbach, Proc. Natl. Acad. Sci. U.S.A. 2004, 101, 5461. d) G. Roelfes, B. L. Feringa, Angew. Chem., Int. Ed. 2005, 44, 3230. e) E. Yashima, K. Maeda, Macromolecules 2008, 41, 3. f) Y. Okamoto, J. Polym. Sci., Part A: Polym. Chem. 2009, 47, 1731. g) K. Miwa, Y. Furusho, E. Yashima, Nat. Chem. 2010, 2, 444.

6 T. Yamada, Y. Nagata, M. Suginome, Chem. Commun. 2010, 46, 4914.

7 a) T. Yamamoto, M. Suginome, Angew. Chem., Int. Ed. 2009, 48, 539. b) T. Yamamoto, T. Yamada, Y. Nagata, M. Suginome, J. Am. Chem. Soc. 2010, 132, 7899. c) T. Yamamoto, Y. Akai, Y. Nagata, M. Suginome, Angew. Chem., Int. Ed. 2011, 50, 8844.

8 a) H. Noguchi, K. Hojo, M. Suginome, J. Am. Chem. Soc. 2007, 129, 758. b) H. Noguchi, T. Shioda, C.-M. Chou, M. Suginome, Org. Lett. 2008, 10, 377.

9 H. Ihara, M. Suginome, J. Am. Chem. Soc. 2009, 131, 7502.

10 H. Ihara, M. Koyanagi, M. Suginome, Org. Lett. 2011, 13, 2662.

11 R. M. Al-Zoubi, D. G. Hall, Org. Lett. 2010, 12, 2480.

12 For nondirected halogenation of organoboronic acids and esters, see: a) H. G. Kuivila, L. E. Benjamin, C. J. Murphy, A. D. Price, J. H. Polevy, J. Org. Chem. 1962, 27, 825. b) D. Qiu, F. Mo, Z. Zheng, Y. Zhang, J. Wang, Org. Lett. 2010, 12, 5474.

13 General procedure: $\mathrm{ICl}(10 \mu \mathrm{L}, 0.2 \mathrm{mmol})$ was added to a solution of $\mathrm{ArB}$ (aam) $(0.1 \mathrm{mmol})$ in $\mathrm{CH}_{2} \mathrm{Cl}_{2}$ at $-78^{\circ} \mathrm{C}$. After $18 \mathrm{~h}, 2-$ methyl-2-butene $(32 \mu \mathrm{L}, 0.3 \mathrm{mmol})$ was added to the solution, which was stirred for $5 \mathrm{~min}$ at room temperature. The mixture was subjected to column chromatography on Florisil ${ }^{\circledR}$ (eluent: hexane-AcOEt (10:1) to pure chloroform), giving $o$-iodonated product 3 .

14 a) T. Ishiyama, J. Takagi, K. Ishida, N. Miyaura, N. R. Anastasi, J. F. Hartwig, J. Am. Chem. Soc. 2002, 124, 390. b) T. Ishiyama, J. Takagi, J. F. Hartwig, N. Miyaura, Angew. Chem., Int. Ed. 2002, $41,3056$.

15 A. F. Littke, C. Dai, G. C. Fu, J. Am. Chem. Soc. 2000, 122, 4020.

16 A mixture of 3a $(69.6 \mathrm{mg}, 0.20 \mathrm{mmol})$, phenylboronic acid (29.3 mg, $0.24 \mathrm{mmol}), \quad \mathrm{Pd}(\mathrm{OAc})_{2} \quad(2.24 \mathrm{mg}, 0.01 \mathrm{mmol})$, and $\mathrm{K}_{3} \mathrm{PO}_{4}(84.8 \mathrm{mg}, 0.40 \mathrm{mmol})$ in THF $(0.4 \mathrm{~mL})$ was stirred for $11 \mathrm{~h}$ at $50{ }^{\circ} \mathrm{C}$. The solvent was evaporated in vacuo. The coupling product $5(55.1 \mathrm{mg}, 92 \%)$ was isolated by column chromatography on silica gel (eluent: hexane-AcOEt $(10: 1)$ to pure chloroform).

17 Supporting Information is available electronically on the CSJJournal Web site, http://www.csj.jp/journals/chem-lett/index.html. 